\title{
Investigating Wild Berries as a Dietary Approach to Reducing the Formation of Advanced Glycation Endproducts: Chemical Correlates of In Vitro Antiglycation Activity
}

\author{
Cory S. Harris • Alain Cuerrier • Erin Lamont • \\ Pierre S. Haddad • John T. Arnason • \\ Steffany A. L. Bennett • Timothy Johns \\ Published online: 22 January 2014 \\ (C) The Author(s) 2014. This article is published with open access at Springerlink.com
}

\begin{abstract}
Evidence supports the health promoting benefits of berries, particularly with regard to the prevention and management of chronic diseases such cardio- and cerebrovascular disease, diabetes and Alzheimer's disease. Two related pathophysiological features common to many of these conditions are oxidative stress and the accumulation of advanced glycation endproducts (AGEs). Whereas antioxidant properties are wellestablished in several species of berries and are believed central to their protective mechanisms, few studies have investigated the effects of berries on AGE formation. Here, employing a series of complementary in vitro assays, we evaluated a collection of wild berry extracts for 1) inhibitory effects on fluorescent-AGE and $\mathrm{N} \varepsilon$ - (carboxymethyl)lysine-albumin adduct formation, 2) radical scavenging activity and 3) total phenolic and anthocyanin content. All samples reduced AGE formation in a concentration-dependent manner that correlated positively with each extract's total phenolic content and, to a lesser degree, total anthocyanin content. Inhibition of AGE
\end{abstract}

\section{T. Johns}

School of Dietetics and Human Nutrition, McGill University,

Montréal, QC, Canada

C. S. Harris $(\bowtie) \cdot$ E. Lamont $•$ J. T. Arnason

Department of Biology, University of Ottawa, 30 Marie Curie, Ottawa, Canada K1N 6N5

e-mail: charris@uottawa.ca

S. A. L. Bennett

Department of Biochemistry, Microbiology, and Immunology, University of Ottawa, 30 Marie Curie, Ottawa, Canada K1N 6N5

\section{A. Cuerrier}

Département de sciences biologiques, Université de Montréal, Montréal, QC, Canada

\section{P. S. Haddad}

Département de pharmacologie, Université de Montréal, Montréal, QC, Canada formation was similarly related to radical scavenging activities. Adding antiglycation activity to the list of established functional properties ascribed to berries and their phenolic metabolites, our data provide further insight into the active compounds and protective mechanisms through which berry consumption may aid in the prevention and treatment of chronic diseases associated with AGE accumulation and toxicity. As widely available, safe and nutritious foods, berries represent a promising dietary intervention worthy of further investigation.

Keywords Fruits · Aging $\cdot$ Chronic disease $\cdot$ Oxidative stress $\cdot$ Radical scavenging $\cdot$ Polyphenolics $\cdot$ Anthocyanins

\section{Introduction}

The potential benefits of fruit consumption to human health have long been recognized. Recently, several berries ${ }^{1}$ have emerged as excellent sources of phytonutrients with putative protective effects toward age-related chronic diseases [1]. Promising evidence in human, animal and cellular studies specifically links berry consumption to lower risk of cardiovascular disease, diabetes and associated complications, cancer, and neurodegenerative diseases [2-5]. In addition to providing a valuable source of vitamins, minerals, and dietary fiber, berries contain a diversity of secondary metabolites, most notably phenolics, which show complex biological activity [6].

Berry phenolics range in structural complexity, from simple phenolic acids to polyphenolic tannins. Although present in many fruits, certain types of berries are remarkably rich in phenolic metabolites - particularly anthocyanins [7]. Responsible for the red, blue and purple colours characteristic of many

\footnotetext{
${ }^{1}$ In this paper, the term 'berry' is used in reference to small, soft fruits and includes fruits such as raspberry and strawberry that, botanically, are not true berries.
} 
berries, anthocyanins are extensively studied and often listed as medicinal ingredients of berry-based health products. Beyond antioxidant properties, berry phenolics (including anthocyanins) display anti-inflammatory, cardioprotective, neuroprotective and hypoglycemic activities through modulation of multiple signaling pathways implicated in the development of chronic and degenerative diseases [8-10]. Many phenolics also inhibit the formation of advanced glycation endproducts (AGEs) [11].

The accumulation and ensuing physiological consequences of AGEs often appear in patients with diabetes, cardiovascular, renal and neurodegenerative diseases as well as some types of cancer $[12,13]$. Produced through non-enzymatic reactions between reducing sugars and proteins, nucleic acids, or lipids, AGEs induce oxidative stress and molecular cross linkages that cause cellular and tissue damage by impairing protein function and clearance [14]. Several AGEs, such as $\mathrm{N} \varepsilon$-(carboxymethyl)lysine (CML), activate the cell surface AGE receptor (RAGE) to initiate NF- $\mathrm{kB}$ and associated proinflammatory signaling pathways $[14,15]$. Whereas AGEs are produced endogenously under normal physiological conditions, they accumulate with age, developing more readily in hyperglycaemic and oxidative conditions. Despite the known antioxidant activity of berries and antiglycation activity of related phenolics, only few individual species have been assessed for effects on AGE formation [16,17]. In these studies, phenolic metabolites are consistently identified as active constituents [16].

Here, using complementary in vitro assays, we evaluate 12 species of wild berries collected from northern Québec, Canada, for their effects on AGE formation. Predicting that antiglycation activity will correlate positively with both phenolic content and anti-oxidant activity, we also assess each extract for total phenolic content, anthocyanin content and radical scavenging capacity.

\section{Materials and Methods}

Reagents Chemicals and solvents were purchased from Fisher Scientific (Ottawa, ON, Canada) unless otherwise specified.

Plant Materials and Extraction Ripe berries and voucher specimens were collected from various locations in Québec, Canada. Upon maturity (August-September), samples were harvested, cleaned, and frozen on site prior to transportation to the University of Ottawa for extraction. Voucher specimens were deposited in the University of Ottawa Herbarium in Ottawa, Canada, with identities confirmed by Dr. Alain Cuerrier. Twenty grams of frozen berries from each collection were lyophilized to dryness, crushed with a mortar and pestle then extracted three times with $25 \mathrm{~mL}$ of $80 \%$ ethanol per $\mathrm{g}$ dry material. Filtered extracts were pooled prior to drying using a Speedvac System AE52010 (Savant, Halbrook, NY) at $43{ }^{\circ} \mathrm{C}$ followed by lyophilization. Dried extracts were stored at $4{ }^{\circ} \mathrm{C}$ in darkness.
AGE Formation Assay Effects on AGE formation were determined as previously described [16]. Briefly, $100 \mathrm{mM}$ sodium phosphate monobasic monohydrate buffer ( $\mathrm{pH}$ 7.4) with $100 \mathrm{mM}$ glucose/100 mM fructose (BDH Chemicals Ltd., Toronto, ON) and bovine serum albumin (BSA) (Sigma Aldrich, St. Louis, MO, USA) $(1 \mathrm{mg} / \mathrm{mL})$ were incubated with vehicle (negative control), berry extract (treatment), or quercetin (positive control) in darkness for seven days at $37^{\circ} \mathrm{C}$ on a mechanical shaker (Series 25 Incubator Shaker, New Brunswick Scientific Co. Inc., Edison, NJ). Each plate included positive and negative controls as well as replicates without BSA to correct for analyte autofluorescence and without sugar to: 1) control for non-AGE-derived fluorescence of BSA, and 2) serve as a negative control for immunochemical assessments. Extracts were tested at concentrations of $12.5-400 \mu \mathrm{g} / \mathrm{ml}$, in quadruplicate, on at least three separate occasions.

Detection and Quantitation of Fluorescent AGEs and CMLBSA Adducts Fluorescent AGEs were measured at excitation and emission wavelengths of 355 and $460 \mathrm{~nm}$, respectively, using a SpectraMax M5 microplate reader (Molecular Devices, Sunnyvale, California). After measurement, plates were sealed with parafilm and stored at $-20{ }^{\circ} \mathrm{C}$ for immunochemical analyses. Percent inhibition was calculated with corrected fluorescence values $(\mathrm{F}): \%$ inhibition $=\left[\left(\mathrm{F}_{\text {negative }}-\mathrm{F}_{\text {experimental }}\right) /\right.$ $\left.\left(\mathrm{F}_{\text {negative }}\right)\right] \times 100 \%[18] . \mathrm{IC}_{50}$ concentrations, defined as the amount of extract $(\mu \mathrm{g} / \mathrm{ml})$ or positive control $(\mu \mathrm{M})$ required to reduce AGE formation by $50 \%$ relative to the negative control, were determined by logarithmic regression analyses $(n=3-4)$.

To detect and quantitate CML-BSA adduct formation [18], samples from control and extract-treated wells were first concentrated using Ultracel YM-10 membrane centrifugal filters (Millipore, Billerica, MA, USA). BSA concentrations were established by Bio-Rad DC Protein assay Kit (Bio-Rad Laboratories Ltd., Mississauga, ON, CAN). After protein separation by SDS-PAGE under reducing conditions, Western blot analyses were performed using mouse monoclonal antibodies targeted against CML-BSA adducts (1:1000, Clone 318003, R \& D Systems, Minneapolis, MN, USA) and goat anti-mouse IgG polyclonal antibodies conjugated with horseradish peroxidase $(1: 1000, R$ \& D Systems). Blots were treated with SuperSignal West Pico (MJS BioLynx Inc) to visualize adducts.

To qualitatively evaluate concentration-dependent effects, protein samples treated with 25,50 , and $100 \mu \mathrm{g} / \mathrm{mL}$ of the same extract were loaded on a single gel. Quantitative comparisons were conducted on blots of samples treated with different extracts administered at $50 \mu \mathrm{g} / \mathrm{mL}$. Gels stained with Coomassie Blue and photographed following electrophoresis served as loading controls. Immunoreactive and Coumassie stained bands were quantified by image densitometry (ImageJ software v.1.38X, National Institutes of Health, Bethesda, MD). After correcting for protein loading, we calculated percent inhibition relative to vehicle control $(n=4-6)$. 
Measurement of Total Phenolic and Total Anthocyanin Content Total phenolic content (TPH) was determined via a modified Folin-Ciocalteau method [19]. Freshly diluted Folin-Ciocalteau reagent (BDH, Toronto, ON) was combined with extract re-solubilized in $80 \%$ ethanol and, after 5 min of equilibration, $7.5 \%$ anhydrous $\mathrm{NaHCO}_{3}$ solution. After $2 \mathrm{~h}$ incubation at $23{ }^{\circ} \mathrm{C}$, absorbance was measured at $725 \mathrm{~nm}$ and TPH values were calculated and expressed as quercetin (Sigma, Oakville, ON) equivalents. Experiments were conducted in quadruplicate on at least three separate occasions $(n=3-4)$.

Total monomeric anthocyanin content (TMAC) was measured following the acid-differential method [20]. Duplicate samples of each berry extract were dissolved in $0.025 \mathrm{M}$ potassium chloride buffer, one adjusted to $\mathrm{pH} 1.0$ and the other to $\mathrm{pH} 4.5$ using $0.4 \mathrm{M}$ sodium acetate buffer. After 15 min of incubation at RT, absorbance values at 496 and $700 \mathrm{~nm}$ were obtained with a Beckman DU-640 Spectrophotometer (Fullerton, CA). TMAC was calculated and expressed as cyanidin-3-glucoside (Fluka, Lyon, France) equivalents using corresponding molar absorptivity $(26,900 \mathrm{~L} / \mathrm{cm} \cdot \mathrm{mol})$ and molecular weight $(449.2 \mathrm{~g} / \mathrm{mol})$. Experiments were conducted in quadruplicate on three or more occasions $(n=3-4)$.

Radical Scavenging Assays Oxygen radical absorbance capacity (ORAC) was measured as previously described [18] in $75 \mathrm{mM}$ phosphate buffer solution (PBS), pH 7.0. Freshly prepared vehicle (50\% MeOH/50\% PBS), Trolox (0.006$12.5 \mu \mathrm{M})$, ascorbic acid (0.006-12.5 $\mu \mathrm{M})$, quercetin (0.002$3.13 \mu \mathrm{M})$ or berry extract $(0.006-12.5 \mu \mathrm{g} / \mathrm{mL})$ were loaded in black 96-well microplates, mixed with $0.08 \mu \mathrm{M}$ fluorescein and allowed to incubate at $37{ }^{\circ} \mathrm{C}$ for $10 \mathrm{~min}$ before adding $150 \mathrm{mM}$ AAPH. Fluorescence was monitored with a Synergy HT Multi-detection microplate reader (BioTek Instruments, Inc., Winooski, VT) every three min for $90 \mathrm{~min}$ at excitation and emission wavelengths of $485 \mathrm{~nm}$ and $530 \mathrm{~nm}$, respectively. ORAC values were calculated as $\mu \mathrm{M}$ Trolox equivalents per mg dried extract as determined from at least four separate experiments $(n=4-5)$.

A modified 1,1-diphenyl-2-picrylhydrazyl (DPPH) radical assay [18] provided a second measure of free radical scavenging activity. Ascorbic acid $(0-60 \mu \mathrm{M})$, quercetin $(0-60 \mu \mathrm{M})$, or extract $(0-1,000 \mathrm{mg} / \mathrm{mL})$ dissolved in methanol was combined with $100 \mu \mathrm{M}$ DPPH and allowed to stand at RT for $10 \mathrm{~min}$ before we measured absorbance at $517 \mathrm{~nm}$ using a Beckman DU 640 spectrophotometer. $\mathrm{EC}_{50}$, the concentration of extract $(\mu \mathrm{g} / \mathrm{mL})$ or positive control $(\mu \mathrm{M})$ required to scavenge $50 \%$ of radicals, was determined by linear regression analyses $(n=4)$ with relative scavenging capacity expressed as $\%$ ascorbic acid equivalents $\left(\% \mathrm{AAE}=\left[\left(\mathrm{EC}_{50}\right)_{\text {ascorbic acid }} /\right.\right.$ $\left.\left(\mathrm{EC}_{50}\right)_{\text {treatment }}\right] \times 100 \%$.

Statistical Analyses Results are expressed as means \pm SEM. Pearson's correlation analyses were used to investigate relationships between TPH, TMAC, antiglycation and radical scavenging activities, using Log-transformed data, as required. Correlation coefficients, coefficients of determination $\left(\mathrm{r}^{2}\right)$ and P-value estimates were calculated using S-Plus 8.0 statistical software (Insightful Corp., Seattle, WA).

Table 1 List of sampled berry species with collection details and extraction data

\begin{tabular}{|c|c|c|c|c|c|c|}
\hline Species & Family & Common name & Source ${ }^{a}$ & Colour & $\%$ water $^{\mathrm{b}}$ & $\%$ yield $^{\mathrm{c}}$ \\
\hline Arctous alpina $\mathrm{L}$. & Ericaceae & Black bearberry & 1 & Dark purple & 79.5 & 35.6 \\
\hline Cornus canadensis $\mathrm{L}$. & Cornaceae & Bunchberry & 2 & Red & 89 & 48.8 \\
\hline Empetrum nigrum L. & Ericaceae & Crowberry & 2 & Dark purple & 86 & 42.1 \\
\hline Juniperus communis L. & Pinaceae & Common juniper & 2 & Blue & 68 & 47.2 \\
\hline Ribes glandulosum Grauer & Grossulariaceae & Swamp currant & 2 & Red & 78.5 & 64.8 \\
\hline Ribes triste Pall. & Grossulariaceae & Smooth currant & 2 & Red & 76 & 43.5 \\
\hline Rubus chamaemorus L. & Rosaceae & Cloudberry & 1 & Orange & 84 & 62.7 \\
\hline Sorbus decora (Sarg.) CK Schneid. & Rosaceae & Showy mountain ash & 2 & Orange-red & 81 & 72.8 \\
\hline Vaccinium angustifolium Ait. & Ericaceae & Lowbush blueberry & 3 & Blue & 85 & 74.1 \\
\hline Vaccinium oxycoccus L. & Ericaceae & Bog cranberry & 4 & Red & 77.5 & 44.0 \\
\hline Vaccinium uliginosum L. (A) & Ericaceae & Bog bilberry & 1 & Blue & 84.5 & 73.3 \\
\hline V. uliginosum L. (B) & Ericaceae & & 2 & Blue & 85.5 & 76.0 \\
\hline V. uliginosum L. (C) & Ericaceae & & 2 & Dark purple & 87 & 78.1 \\
\hline Vaccinium vitis-idaea $\mathrm{L}$. & Ericaceae & Lingonberry & 4 & Crimson & 85 & 79.2 \\
\hline
\end{tabular}

${ }^{a}$ Berry samples were collected in August and September near: 1) Kuujuac, Québec, Canada; 2) Great Whale River, Québec, Canada; 3) La Vérendrye Wildlife Reserve, Québec, Canada; 4) Chibougamau, Québec, Canada

${ }^{\mathrm{b}}$ Percent water of berry samples is expressed as $[1-(\mathrm{g}$ dry wt $/ \mathrm{g}$ fresh wt $)] \times 100 \%$

${ }^{\mathrm{c}}$ Percent yield is expressed as (g extract/g dry wt) $\times 100 \%$ 


\section{Results}

Fourteen samples representing 12 species are detailed in Table 1. Three samples of $V$. uliginosum were included to gauge potential intra-species variation. Water content was over $75 \%$ for all berries except J. communis, a modified cone more frequently used for medicine than food. Extraction yields varied from 36 to $79 \%$ of dry weight (Table 1).

Inhibition of Non-Enzymatic Formation of AGEs Fluorometric analyses of AGEs revealed concentration-dependent inhibition by all extracts but with varying potencies (Fig. 1a). Whereas most $\mathrm{IC}_{50}$ values were above $50 \mu \mathrm{g} / \mathrm{mL}$, those of five extracts ( $J$. communis, A. alpina, E. nigrum, $V$. vitis-idaea, and $R$. glandulosum) were approximately 100 -fold lower than the weakest inhibitor, $R$. chamaemorus (Table 2). Quercetin, a commonly occurring flavonoid with established AGE inhibiting activity, exhibited an $\mathrm{IC}_{50}$ of $6.1 \mu \mathrm{M}$ while ascorbic acid elicited no effect at the tested concentrations $(0.2-200 \mu \mathrm{M})$. Immunochemically detected CML-BSA adducts in vehicle-control samples (with BSA+glucose/fructose) established the uninhibited level of glycation (100\%), vehicle with BSA alone yielded no adducts, and quercetin $(16 \mu \mathrm{M})$ reduced adduction by over $80 \%$ (Fig. 1b). All extracts inhibited CML-BSA adduct formation in a concentration-dependent manner (data not shown) with relative activities (at $50 \mu \mathrm{g} / \mathrm{mL}$ ) illustrated in Fig. 1b. Percent inhibition relative to the vehicle-controls ranged from $37 \%$
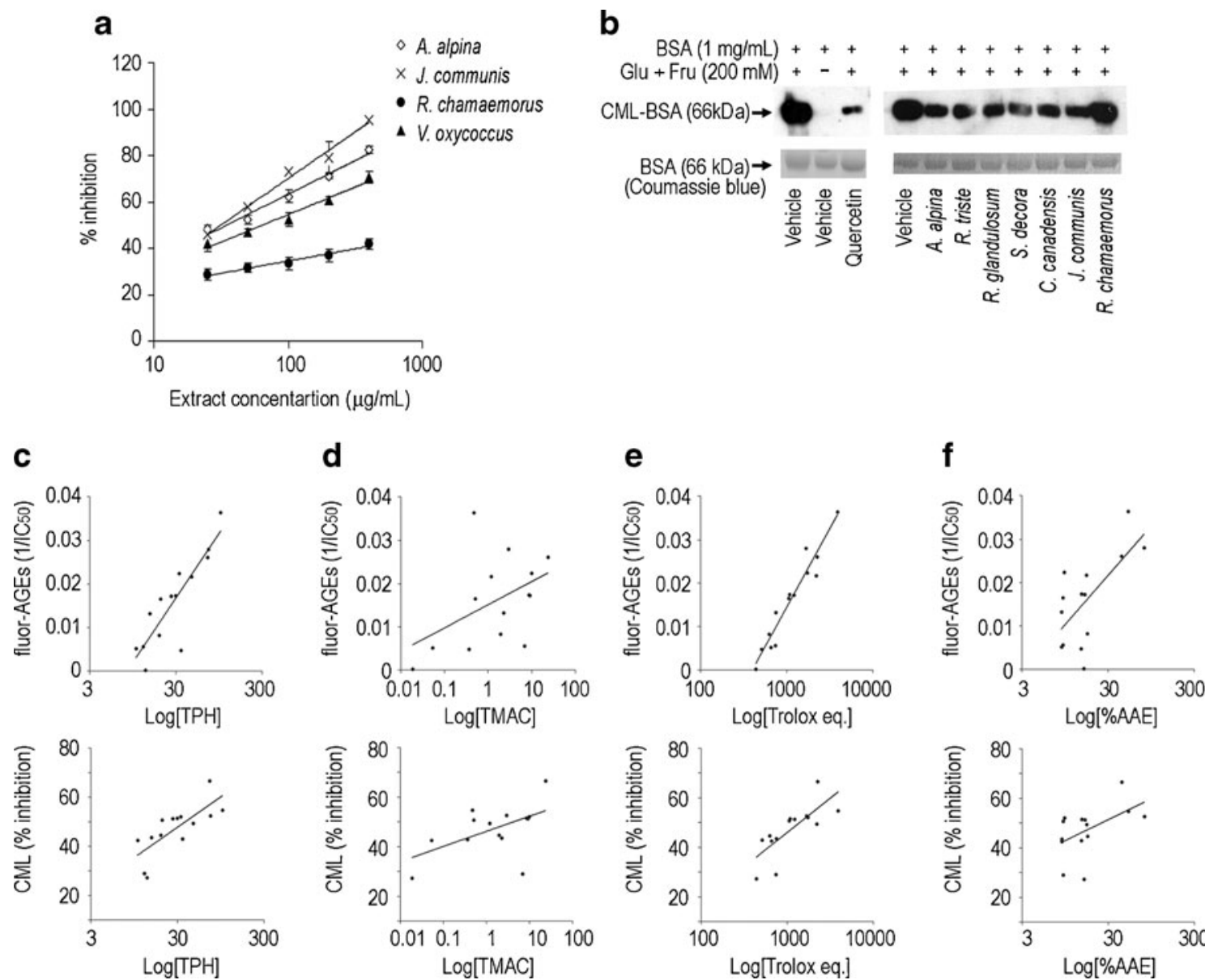

Fig. 1 Inhibition of AGE formation by representative berry extracts and correlations with phenolic and anthocyanin content as well as radical scavenging activity. a Concentration-dependent inhibition of fluorescent AGE formation by various extracts (mean $\pm \mathrm{SEM}, n=3-4$ ). Corresponding $\mathrm{IC}_{50}$ values are listed in Table 2. b Western blot using CML-specific antibodies on protein samples incubated with glucose/fructose, vehicle, and quercetin (positive control, $16 \mu \mathrm{M}$ ), or $50 \mu \mathrm{g}$ of berry extract. BSA incubated without sugar was used as a negative control for the CML-BSA antibody. Each SDS-PAGE separation was performed in duplicate; the first was used for Western blotting (upper panels) and the second to control for protein loading (Coomassie Blue staining - lower panels). cf Pearson's correlation analyses of fluorescent AGE (fluor-AGE) and
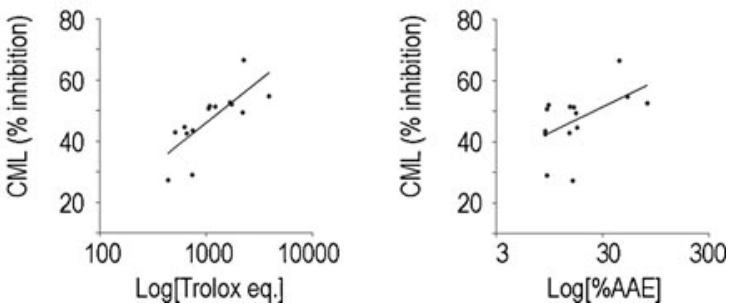

carboxymethyl lysine (CML) inhibition relative to total phenolic content (TPH, expressed as quercetin equivalents), total monomeric anthocyanin content (TMAC, expressed as cyanidin-3-glucoside equivalents), oxygen radical absorbance capacity (ORAC, expressed as Trolox equivalents), and 1,1-diphenyl-2-picrylhydrazyl (DPPH) radical scavenging activity expressed as percent ascorbic acid equivalents (\% AAE). [(c) fluorAGE vs. TPH: $p<0.001 ; r^{2}=0.760$; CML vs TPH: $p=0.001 ; r^{2}=0.594$; (d) fluor-AGE vs. TMAC: $p=0.097 ; r^{2}=0.213$; CML vs TMAC: $p=$ $0.047 ; r^{2}=0.291$; (e) fluor-AGE vs. Trolox eq: $p<0.001 ; r^{2}=0.928$; CML vs Trolox eq: $p=0.002 ; r^{2}=0.578$; (f) fluorAGE vs. $\% A A E$ : $p<0.008 ; r^{2}=0.452$; CML vs \%AAE: $p=0.059 ; r^{2}=0.266$ ] 
for $R$. chamaemorus to $77 \%$ for E. nigrum (Table 2) and correlated highly with $\mathrm{IC}_{50}$ values obtained in the fluorescence assay $\left(p<0.001 ; r^{2}=0.651\right)$.

Total Phenolic and Anthocyanin Content TPH ranged from 10 to $100 \mathrm{mg}$ quercein equivalents per g extract, highest in $J$. communis, A. alpina, and E. nigrum extracts and lowest in $S$. decora, $V$. angustifolium and $R$. chamaemorus, extracts (Table 2). TMAC, a subclass of phenolics, was expectedly lower than TPH in all extracts and was highest in Ericaceous berries (with the exception of $V$. oxycoccus). No correlation, however, was observed between the two measures.

Radical Scavenging Activity Extracts of J. communis, $E$. nigrum, and $R$. glandulosum generated the strongest scavenging effects with ORAC values over 2,000 $\mu \mathrm{M}$ Trolox equivalents (TE). In contrast, the TE of six extracts (C. canadensis, $R$. triste, $R$. chamaemorus, $S$. decora, $V$. angustifolium and $V$. oxycoccus) was below $700 \mu \mathrm{M}$ (Table 2). Whereas the activity of ascorbic acid and the most potent extract (J. communis) were similar, that of quercetin was 20 - times greater. In the DPPH assay, a similar 10-fold difference in activity was observed between the strongest and weakest radical scavenging extracts. Quercetin $\left(\mathrm{EC}_{50}=12.3 \pm 0.8 \mu \mathrm{M}\right.$, $205 \%$ AAE) was twice as effective as ascorbic acid $\left(\mathrm{EC}_{50}=\right.$ $25.4 \pm 1.2 \mu \mathrm{M})$ with extracts of $A$. alpina (78 \% AAE), $J$. communis (51\% AAE) and E. nigrum (43\% AAE) demonstrating the most potent activities among berry samples (Table 2). Extracts of $S$. decora and the four species of Vaccinium demonstrated much weaker activity $(<15 \%$ AAE). ORAC and DPPH results were significantly correlated $\left(p=0.028 ; r^{2}=0.342\right)$.

Correlations Between Biochemical Activities and Phenolic or Anthocyanin Content Pearson's correlation analyses detected several significant, positive relationships among the investigated variables (Fig. 1). TPH was highly correlated with all measures of antiglycation and radical scavenging activity but correlations between TMAC and AGE inhibition were less pronounced, only significant in relation to CML-BSA adducts (Fig. 1c-d). Inhibition of AGE formation, particularly fluorescent AGEs, was strongly correlated with ORAC scores

Table 2 Antiglycation activities, total phenolic and total anthocyanin contents, and radical scavenging activities of berry extracts

\begin{tabular}{|c|c|c|c|c|c|c|}
\hline \multirow[t]{2}{*}{ Treatment } & \multicolumn{2}{|l|}{ AGE inhibition } & \multicolumn{2}{|c|}{ Phenolic \& anthocyanin content } & \multicolumn{2}{|l|}{ Anti-oxidant activity } \\
\hline & Fluorescent AGE $-\mathrm{IC}_{50}{ }^{\mathrm{a}}$ & CML-BSA \% inhibition ${ }^{b}$ & $\mathrm{TPH}^{\mathrm{c}}(\mathrm{mg} / \mathrm{g})$ & $\operatorname{TMAC}^{\mathrm{d}}(\mathrm{mg} / \mathrm{g})$ & ORAC $^{\text {e }}$ Trolox eq. & $\mathrm{DPPH}^{\mathrm{f}} \% \mathrm{AAE}$ \\
\hline Quercetin & $6.1 \pm 1.8$ & $81.4 \pm 5.6$ & - & - & $91845 \pm 9437$ & $205 \pm 13.3$ \\
\hline Ascorbic acid & No effect & - & - & - & $3669 \pm 274$ & $100 \pm 4.7$ \\
\hline A. alpine & $35.6 \pm 9.5$ & $62.6 \pm 82.0$ & $71.9 \pm 3.1$ & $2.91 \pm 0.20$ & $1660 \pm 136$ & $75.4 \pm 8.9$ \\
\hline C. canadensis & $120.3 \pm 6.9$ & $54.6 \pm 4.0$ & $19.2 \pm 4.2$ & $1.93 \pm 0.03$ & $624 \pm 38$ & $19.4 \pm 2.2$ \\
\hline E. nigrum & $38.2 \pm 2.5$ & $76.7 \pm 7.2$ & $70.0 \pm 5.7$ & $23.27 \pm 1.37$ & $2247 \pm 225$ & $40.2 \pm 6.9$ \\
\hline J. communis & $27.4 \pm 2.6$ & $64.9 \pm 4.4$ & $99.2 \pm 4.7$ & $0.47 \pm 0.07$ & $3876 \pm 142$ & $48.6 \pm 2.3$ \\
\hline R. glandulosum & $46.0 \pm 4.2$ & $59.4 \pm 5.0$ & $45.4 \pm 6.5$ & $1.17 \pm 0.12$ & $2182 \pm 109$ & $16.8 \pm 2.5$ \\
\hline R. triste & $208.6 \pm 34.4$ & $53.0 \pm 4.4$ & $34.2 \pm 7.7$ & $0.36 \pm 0.15$ & $510 \pm 34$ & $22.8 \pm 5.7$ \\
\hline R. chamaemorus & $4009 \pm 1753$ & $37.4 \pm 14.8$ & $13.2 \pm 2.3$ & $0.02 \pm 0.01$ & $438 \pm 57$ & $19.4 \pm 1.9$ \\
\hline S. decora & $192.7 \pm 37.1$ & $52.6 \pm 1.5$ & $10.3 \pm 1.7$ & $0.05 \pm 0.01$ & $657 \pm 88$ & $10.8 \pm 1.7$ \\
\hline V. angustifolium & $177.8 \pm 22.4$ & $39.0 \pm 3.7$ & $12.4 \pm 2.1$ & $6.81 \pm 0.50$ & $732 \pm 38$ & $9.5 \pm 1.6$ \\
\hline V. oxycoccus & $60.2 \pm 1.5$ & $60.9 \pm 4.1$ & $19.8 \pm 3.1$ & $0.50 \pm 0.13$ & $1049 \pm 260$ & $7.7 \pm 0.7$ \\
\hline V. uliginosum (A) & $75.5 \pm 14.7$ & $53.6 \pm 3.9$ & $14.9 \pm 1.9$ & $2.27 \pm 0.03$ & $747 \pm 29$ & $8.0 \pm 0.7$ \\
\hline V. uliginosum (B) & $57.5 \pm 14.6$ & $61.5 \pm 7.1$ & $29.8 \pm 5.1$ & $8.55 \pm 0.32$ & $1075 \pm 132$ & $13.8 \pm 2.2$ \\
\hline V. uliginosum $(C)$ & $57.8 \pm 8.2$ & $61.4 \pm 4.4$ & $26.3 \pm 6.4$ & $9.07 \pm 0.35$ & $1216 \pm 112$ & $15.3 \pm 3.2$ \\
\hline V. vitis-idaea & $44.5 \pm 12.4$ & $62.1 \pm 4.7$ & $32.6 \pm 2.2$ & $9.84 \pm 0.37$ & $1725 \pm 66$ & $8.1 \pm 0.8$ \\
\hline
\end{tabular}

${ }^{\mathrm{a}} \mathrm{IC}_{50}$ concentrations \pm SEM calculated as the extract $(\mu \mathrm{g} / \mathrm{mL})$ or control $(\mu \mathrm{M})$ concentration required to reduce fluorescent $\mathrm{AGE}$ formation by $50 \%$ as determined by regression analysis $(n=3-4)$

$\mathrm{b}_{\%}$ inhibition \pm SEM of $\mathrm{N} \varepsilon$-(carboxymethyl)lysine-BSA (CML-BSA) adduct formation as determined by densitometry of Western blot analyses of purified protein following treatment with sugar, vehicle, $16 \mu \mathrm{M}$ quercetin or $50 \mu \mathrm{g}$ extract $/ \mathrm{mL}(n=4-5)$

${ }^{\mathrm{c}}$ Total phenolic content (TPH) as determined by the Folin-Ciocalteu method, expressed as mg quercetin equivalents/g extract \pm SEM $(n=3-4)$

${ }^{\mathrm{d}}$ Total monomeric anthocyanin content (TMAC) as determined by the acid differential method, expressed as mg cyaniding-3-glucoside equivalents/g extract $\pm \operatorname{SEM}(n=3-4)$

${ }^{\mathrm{e}}$ Oxygen radical absorbance capacity (ORAC) is expressed in $\mu \mathrm{M}$ Trolox equivalents $\pm \mathrm{SEM}$ at a concentration of $1 \mathrm{mg} / \mathrm{mL}$ for extracts and $1 \mathrm{mM}$ for quercetin and ascorbic acid $(n=4-5)$

${ }^{\mathrm{f}}$ Percent ascorbic acid equivalents (\% AAE) as determined by the 1,1-diphenyl-2-picrylhydrazyl (DPPH) radical scavenging assay ( $\left.n=4-5\right)$ 
(Fig. 1e) while DPPH radical scavenging correlated less robustly with fluorescent AGE formation and insignificantly with CML-BSA adduction (Fig. 1f).

\section{Discussion}

Within this collection of Canadian berry extracts, antiglycation activity correlates strongly with radical scavenging activity and total phenolic content as well as weakly with total anthocyanin content. Given that the AGE-inhibiting effects of other small fruits - muscadine grape [17], lingonberry [16] and acerola [21] - have been attributed to phenolic metabolites including but not limited to anthocyanins, this finding is not surprising. As such, while anthocyanins are effective AGE inhibitors contributing to activity, TPH appears more pertinent than TMAC to antiglycation (and radical scavenging) activity, in general.

Inhibition of AGE formation correlated more strongly with ORAC data than with those for DPPH scavenging, likely reflecting the greater involvement of peroxyl- over DPPHlike radicals in glycation reactions and/or inhibitory mechanisms. The relative activities of quercetin and ascorbic acid both commonly found in berries - provide additional insight since 1) quercetin was 20 times more effective than ascorbic acid in the ORAC assay but only twice so in the DPPH assay, and 2) quercetin potently inhibits AGE formation while ascorbic acid had no effect in our system (and enhances glycaton in others [22]). Apparently, not all antioxidants prevent glycation. Moreover, antiglycation activity is determined by more than antioxidant properties. Indeed, studies on individual plant phenolics report distinct structural determinants of antioxidant and antiglycation activity [11,23].

Of the three samples of $V$. uliginosum, the two James Bay collections $(\mathrm{B} \& \mathrm{C})$ yielded nearly identical results in all assays. Sample A, collected in the far north, however, contained fewer phenolics and anthocyanins and displayed correspondingly weaker activities, highlighting the impact of intra-species variation. Because berry composition depends on genetic, developmental, seasonal, ecological and postharvest factors, the precise activities and rankings reported here are specific to the collected samples. However, as similar correlations between phenolics, radical scavenging, and AGE inhibition are found among medicinal plants of Canada [18] and Thailand [24], the identified relationships likely extend to other collections of berries and phenoliccontaining plant foods.

Whereas the extract concentrations required to significantly reduce AGE formation exceeded $10 \mu \mathrm{g} / \mathrm{mL}$, often by an order of magnitude, individual phenolics are active at concentrations below $1 \mu \mathrm{g} / \mathrm{mL}$ [18]. Despite low bioavailability resulting from poor absorption and rapid metabolic breakdown, plasma levels of food-derived phenolics can reach low $\mu \mathrm{M}$ concentrations [25]. Consumption of berries increases circulating levels of intact phenolics as well as their metabolites [26], some of which retain their antiglycation activity [27]. Increasing consumption of berries, particularly phenolic-rich species such as E. nigrum and A. alpina, may thus aid in the prevention and management of AGE-related conditions like diabetes and associated complications. Given that this is the first study to explore antiglycation relationships within a collection of plant-based foods, our results set the stage for future antiglycation research of phenolics and their human and microbial metabolites in cells, animals, or humans.

In northern Québec, access to fresh fruits and vegetables is limited and expensive when available. Whereas other wild fruits are scarce, berries are plentiful and contribute valuably to the traditional diet of the region's indigenous communities, which, like many others around the world, suffer increased risk of diabetes and diabetic complications [28,29]. Representing a culturally relevant and locally accessible source of needed nutrients and plant phenolics, berries warrant continued investigation as dietary means of improving aboriginal health.

Acknowledgments These studies were funded by a Team grant from the Canadian Institutes of Health Research. CSH was supported by a NSERC and CIHR Banting Postdoctoral Fellowship. We thank Vicky Fillion and Marc Allard for collecting berry samples near Kuujuak. Special thanks are due to Cree Elders of Eeyou Istchee, their Band Council offices and the Cree Board of Health and Social Services of James Bay. Their trust has enabled a useful exchange between Indigenous knowledge and Western science.

Statement of Conflict of Interest None of the contributing authors has any conflict of interest to declare with regards to the described research or the publication of the result

Open Access This article is distributed under the terms of the Creative Commons Attribution License which permits any use, distribution, and reproduction in any medium, provided the original author(s) and the source are credited.

\section{References}

1. Paredes-López O, Cervantes-Ceja ML, Vigna-Pérez M, HernándezPérez T (2010) Berries: improving human health and healthy aging, and promoting quality life - A review. Plant Foods Hum Nutr 65(3): 299-308

2. Lee IT, Chan YC, Lin CW, Lee WJ, Sheu WH (2008) Effect of cranberry extracts on lipid profiles in subjects with type 2 diabetes. Diabet Med 25(12):1473-1477

3. Seeram NP (2008) Berry fruits for cancer prevention: current status and future prospects. J Agric Food Chem 56(3):630-635

4. Joseph JA, Denisova NA, Arendash G, Gordon M, Diamond D, Shukitt-Hale B, Morgan D (2003) Blueberry supplementation enhances signaling and prevents behavioral deficits in an Alzheimer disease model. Nutr Neurosci 6(3):153-162 
5. Basu A, Rhone M, Lyons TJ (2010) Berries: emerging impact on cardiovascular health. Nutr Rev 68(3):168-177

6. Szajdek A, Borowska E (2008) Bioactive compounds and healthpromoting properties of berry fruits: a review. Plant Foods for Hum Nutr 63(4):147-156

7. Wu X, Beecher GR, Holden JM, Haytowitz DB, Gebhardt SE, Prior RL (2006) Concentrations of anthocyanins in common foods in the United States and estimation of normal consumption. J Agric Food Chem 54(11):4069-4075

8. Galli RL, Shukitt-Hale B, Youdim KA, Joseph JA (2002) Fruit polyphenolics and brain aging: nutritional interventions targeting age-related neuronal and behavioral deficits. Ann N Y Acad Sci 959:128-132

9. Zern TL, Fernandez ML (2005) Cardioprotective effects of dietary polyphenols. J Nutr 135(10):2291-2294

10. Duthie SJ (2007) Berry phytochemicals, genomic stability and cancer: evidence for chemoprotection at several stages in the carcinogenic process. Mol Nutr Food Res 51(6):665-674

11. Wu CH, Yen GC (2005) Inhibitory effect of naturally occurring flavonoids on the formation of advanced glycation endproducts. J Agric Food Chem 53(8):3167-3173

12. Kilhovd BK, Juutilainen A, Lehto S, Ronnemaa T, Torjesen PA, Hanssen KF, Laakso M (2007) Increased serum levels of advanced glycation endproducts predict total, cardiovascular and coronary mortality in women with type 2 diabetes: a population-based 18 year follow-up study. Diabetologia 50(7):1409-1417

13. Munch G, Thome J, Foley P, Schinzel R, Riederer P (1997) Advanced glycation endproducts in ageing and Alzheimer's disease. Brain Res Brain Res Rev 23(1-2):134-143

14. Ulrich P, Cerami A (2001) Protein glycation, diabetes, and aging. Recent Prog Horm Res 56:1-21

15. Bierhaus A, Humpert PM, Morcos M, Wendt T, Chavakis T, Arnold B, Stern DM, Nawroth PP (2005) Understanding RAGE, the receptor for advanced glycation end products. J Mol Med 83(11):876-886

16. Beaulieu LP, Harris CS, Saleem A, Cuerrier A, Haddad PS, Martineau LC, Bennett SA, Arnason JT (2009) Inhibitory effect of the cree traditional medicine wiishichimanaanh (Vaccinium vitisidaea) on advanced glycation endproduct formation: identification of active principles. Phytother Res 24(5):741-747

17. Farrar JL, Hartle DK, Hargrove JL, Greenspan P (2007) Inhibition of protein glycation by skins and seeds of the muscadine grape. Biofactors 30(3):193-200

18. Harris CS, Beaulieu LP, Fraser MH, McIntyre KL, Owen PL, Martineau LC, Cuerrier A, Johns T, Haddad PS, Bennett SA et al (2011) Inhibition of advanced glycation end product formation by medicinal plant extracts correlates with phenolic metabolites and antioxidant activity. Planta Medica 77(2):196-204

19. Farsi DA, Harris CS, Reid L, Bennett SA, Haddad PS, Martineau LC, Arnason JT (2008) Inhibition of non-enzymatic glycation by silk extracts from a Mexican land race and modern inbred lines of maize (Zea mays). Phytother Res 22(1):108-112

20. Guisti MM, Wrolstad, RE (2001) Characterization and measurement of anthocyanins by uv-visible spectroscopy. In: Wrolstad RE (ed) Current protocols in food analytical chemistry. Wiley, New York, F.1.2.1-F.1.2.13

21. Hanamura T, Hagiwara T, Kawagishi H (2005) Structural and functional characterization of polyphenols isolated from acerola (Malpighia emarginata DC.) fruit. Biosci Biotechnol Biochem 69(2):280-286

22. Tupe RS, Agte VV (2010) Role of zinc along with ascorbic acid and folic acid during long-term in vitro albumin glycation. Br J Nutr 103(3):370-377

23. Matsuda H, Wang T, Managi H, Yoshikawa M (2003) Structural requirements of flavonoids for inhibition of protein glycation and radical scavenging activities. Bioorg Med Chem 11(24):5317-5323

24. Kusirisin W, Srichairatanakool S, Lerttrakarnnon P, Lailerd N, Suttajit M, Jaikang C, Chaiyasut C (2009) Antioxidative activity, polyphenolic content and anti-glycation effect of some thai medicinal plants traditionally used in diabetic patients. Med Chem 5(2):139-147

25. Erlund I, Meririnne E, Alfthan G, Aro A (2001) Plasma kinetics and urinary excretion of the flavanones naringenin and hesperetin in humans after ingestion of orange juice and grapefruit juice. $\mathrm{J}$ Nutr 131(2):235-241

26. Koli R, Erlund I, Jula A, Marniemi J, Mattila P, Alfthan G (2010) Bioavailability of various polyphenols from a diet containing moderate amounts of berries. J Agric Food Chem 58(7):3927-3932

27. Pashikanti S, de Alba DR, Boissonneault GA, CervantesLaurean D (2010) Rutin metabolites: novel inhibitors of nonoxidative advanced glycation end products. Free Radic Biol Med 48(5):656-663

28. Hanley AJ, Harris SB, Mamakeesick M, Goodwin K, Fiddler E, Hegele RA, Spence JD, House AA, Brown E, Schoales B et al (2005) Complications of type 2 diabetes among aboriginal Canadians: prevalence and associated risk factors. Diabetes Care 28(8):2054-2057

29. Young TK, Reading J, Elias B, O’Neil JD (2000) Type 2 diabetes mellitus in Canada's first nations: status of an epidemic in progress. Cmaj 163(5):561-566 